Acknowledgements. We thank Professor Holger Erdtman for his kind interest in this work and Cellulosaindustriens Stiftelse, 1959 ars Fond, for financial support.

1. Westfelt, L. Acta Chem. Scand. 20 (1966) 2829.

2. Westfelt, L. Acta Chem. Scand. 20 (1966) 2841.

3. Bowden, K., Heilbron, I. M., Jones, E. R. H. and Weedon, B. C. L. J. Chem. Soc. 194639.

4. Flautt, T. J. and Erman, W. F. J. Am. Chem. Soc. 85 (1963) 3212.

5. de Mayo, P. and Williams, R. E. J. Am. Chem. Soc. 87 (1965) 3275.

6. Patterson, T. S. and McAlpine, I. M. $J$. Chem. Soc. 19282464.

7. Jackson, C. J. and Menke, A. E. J. Am. Chem. Soc. 5 (1883) 270.

8. Trevoy, L. W. and Brown, W. G. J. Am. Chem. Soc. 71 (1949) 1675.

9. Kolbe, M. and Westfelt, L. To be pub. lished.

Received January 25, 1967.

\section{Torsional Motion in Non-ortho Substituted Biphenyls}

\section{O. BASTIANSEN and A. SKANCKE}

Department of Chemistry, University of Oslo, Oslo 3, Norway

$B_{d}^{i}$ iphenyl and its non-ortho substituted derivatives have a planar structure in the crystalline phase, ${ }^{1}$ whereas a nonplanar structure has been observed in the vapour phase..$^{-4}$ In this case the angle $\alpha$ between the two benzene planes was determined to be $42^{\circ}$, and the work indicated that the molecules are far from being rigid. This is in accordance with theoretical calculations combining non-bonded interaction and conjugation energy. The theoretically calculated potential curve exhibits a flat and shallow minimum at $\alpha \simeq 40^{\circ}$.

The purpose of the present work was to estimate the magnitude of the torsional amplitude around the central $\mathrm{C}-\mathrm{C}^{\prime}$ bond. The idea was to study the $3,3^{\prime}-\mathrm{Br} . . \mathrm{Br}$ distance contribution to the electron. diffraction radial-distribution curve for the two molecules, 3,3'-dibromobiphenyl and $3,5,3^{\prime}, 5^{\prime}$-tetrabromobiphenyl.

The angle between the ring planes is calculated by studying several distances that vary with the angle. The tetrabromosubstituted compound was found to be best suited for this study because of the double weight of the angle dependent $\mathrm{Br}_{3} \ldots \mathrm{Br}_{3}{ }^{\prime}$ distances, but the angle seems to be identical in the two compounds. The value $\alpha=45^{\circ}$ was found by averaging the value calculated from different peaks in the radial distribution curve. The shift of the maximum position of the peak in the radial distribution curve with the rotational and vibrational motions is estimated and taken into account.

In a molecular model with an inter-ring angle of $45^{\circ}$ two $\mathrm{Br}_{3} \cdots \mathrm{Br}_{3}{ }^{\prime}$ distances exist. It appears that only the longer one is suited for studies of torsional amplitudes. The peak in the radial distribution curve of the shorter one is badly overlapped by peaks from other angle-dependent distances. The longer distance peak is influenced by the angle independent $\mathrm{Br}_{3} \ldots \mathrm{H}_{4}^{\prime}$ distance only, the contribution of which may easily be subtracted from the curve. In the present work, all calculations of intra-molecular motion are therefore based upon the long $\mathrm{Br}_{3} \cdots \mathrm{Br}_{3}{ }^{\prime}$ distance peak only.

The $\mathrm{Br}_{3} \ldots \mathrm{Br}_{3}{ }^{\prime}$ distances of the di- and tetrabromo-substituted compounds depend upon the angle of twist. The corresponding root-mean-square amplitude, $u$, depends upon the rotational amplitude, $\sigma_{\alpha}$, as well as the non-rotational vibration, here called framework vibration, $u_{\mathrm{f}}$. We assume these two types of motion to be separable. But even with an exact knowledge of the shape of the $\mathrm{Br}$...B $\mathrm{Br}^{\prime}$ peak, it is impossible to obtain both $\sigma_{\alpha}$ and $u_{\mathrm{f}}$ without additional information. If one wants to estimate $\sigma_{\alpha}$, assumptions have to be made concerning $u_{\mathrm{f}}$. In order to obtain a basis for an evalua. tion of the framework vibration, 3,5,4'tribromobiphenyl was chosen as a reference substance. The inter-ring angle, $\alpha$, for this compound was identical with that of the other compounds. The $\mathrm{Br}_{3} \ldots \mathrm{Br}_{4}{ }^{\prime}$ distance is not very different from the $\mathrm{Br}_{3} \cdots \mathrm{Br}_{3}{ }^{\prime}$ distance of the other compounds. But as the $\mathrm{Br}_{4}{ }^{\prime}$ atom lies on the axis of rotation, the $\mathrm{Br}_{3} \cdots \mathrm{Br}_{4}{ }^{\prime}$ distance is independent of $\alpha$. Consequently the corresponding $u$ value is due to framework vibration only. This is the basis for using the $u$ value for the two other compounds, though it can be nothing but a rather rough approximation. 


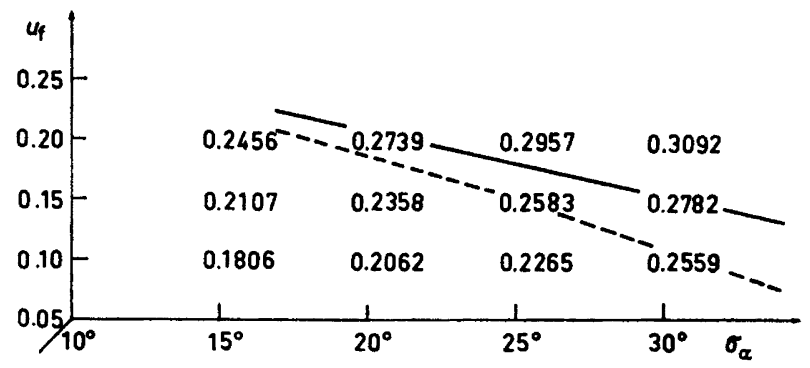

Fig. 1. $u_{\mathrm{f}}$ and $\sigma_{\alpha}$ combinations.

3,3'-Dibromobiphenyl, $\quad \ldots . \quad 3,5,3^{\prime}, 5^{\prime}$-tetrabromobiphenyl.

The $\mathrm{Br}_{3} \cdots \mathrm{Br}_{3}{ }^{\prime}$ peaks are somewhat asymmetric in shape because of the torsion, but $u$ values based on half-width measurements of Gaussian curves were still used for the description. The $\mathrm{Br}_{3} \cdots \mathrm{Br}_{4}{ }^{\prime}$ peak of the tribromosubstituted compound is very nearly Gaussian as would be expected. The $u$ values for $3,5,3^{\prime}, 5^{\prime}$-tetrabromobiphenyl, 3,3'-dibromobiphenyl, and 3,5,4'tribromobiphenyl are $0.26,0.28$, and $0.217 \AA$, respectively.

The $u$ values for $3,3^{\prime}$-dibromobiphenyl and $3,5,3^{\prime}, 5^{\prime}$-tetrabromobiphenyl may be calculated by combining assumed frame. work vibration and assumed torsion. For simplicity, some additional assumptions were made: 1) Framework vibration is harmonic. 2) Framework vibration is independent of $\alpha$. 3) Torsion is harmonic around the equilibrium angle.

The third assumption is rather arbitrary. But for a rough estimate all three assumptions are probably justified, especially if $\sigma_{\alpha}$ is small. Several theoretical radial-distribution curves with different combinations of $u_{f}$ and $\sigma_{\alpha}$ have been calculated by applying a folding procedure. The resultant curves deviate from the Gaussian shape, in accordance with the experimental curves. The $u$ values from different $u_{\mathrm{f}}$ and $\sigma_{\alpha}$ combinations are plotted in the map. The lines give the possible $u_{\mathrm{f}}$ and $\sigma_{\alpha}$ combinations based on the experimental $u$ values of 0.26 and $0.28 \AA$ for $3,5,3^{\prime}, 5^{\prime}$ tetrabromobiphenyl and $\mathbf{3}, \mathbf{3}^{\prime}$-dibromobiphenyl. Assuming framework vibration for these two compounds to be $0.216 \AA$, which is the experimental value for $3,5,4^{\prime}$-tribromobiphenyl, this leads to torsional amplitudes of $17^{\circ}$ and $19^{\circ}$ for the two compounds. This difference may be insignificant, but intuitively a smaller torsion could be expected for a compound with the largest moment of inertia.

A series of rough approximations and assumptions have been made in these calculations. A more sophisticated approach is certainly possible and could relatively easily be carried through. How ever, the experimental data hardly justify a more refined calculation. The diffraction data used for this study are only those associated with the longest $\mathrm{Br}$... Br distance, and this is a very small fraction of the total electron-diffraction intensity.

The $\mathrm{Br}$ atom form factors used in this work are those calculated by Hanson. ${ }^{6}$ According to studies by Strand on bromine substituted benzene derivatives, this choice may not be the best. ${ }^{7}{ }^{8}$ This may also add to the uncertainty.

In spite of all possible sources of error, we believe it is meaningful to conclude that $\sigma_{\alpha}$ for both 3,3'-dibromobiphenyl and $\mathbf{3}, 5,3^{\prime}, 5^{\prime}$-tetrabromobiphenyl are between $15^{\circ}$ and $22^{\circ}$.

The aim of this work was not primarily determination of structure parameters. But for possible comparison with results obtained from other methods, the most important geometric parameters are given in Table 1.

Table 1.

Dist. $\quad$ A

\begin{tabular}{ll}
\hline $\mathrm{C}_{2}-\mathrm{C}_{2}$ & 1.400 \\
$\mathrm{C}_{3}-\mathrm{Br}_{3}$ & 1.880 \\
$\mathrm{C}_{2}-\mathrm{H}_{2}{ }^{\prime}$ & 1.082 \\
$\mathrm{C}_{1}-\mathrm{C}_{1}^{\prime}$ & 1.510 \\
\hline
\end{tabular}


Acknowledgement. The authors want to express their gratitude to Cand.real. Arne Almenningen for having taken the electrondiffraction diagrams.

1. Trotter, J. Acta Cryst. 14 (1961) 1135.

2. Bastiansen, O. Acta Chem. Scand. 3 (1949) 408.

3. Bastiansen, O. Acta Chem. Scand. 4 (1950) 926.

4. Almenningen, A., Bastiansen, $O$. and Fernholt, L. Kgl. Norske Videnskab. Selskabs, Skrifter 1958 No. 4.

5. Fischer.Hjalmars, I. Tetrahedron 19 (1963) 1805.

6. Hanson, H. P. Acta Chem. Scand. 15 (1961) 952.

7. Strand, T. G. J. Chem. Phys. 44 (1966) 1611

8. Strand, T. G. Acta Chem. Scand. To be published.

Received January 24, 1967.

\section{Studies on the Chemistry of Lichens}

\section{7* The Absolute Configuration of Rangiformic Acid BJÖRN AKERMARK}

Department of Organic Chemistry, Royal Institute of Technology, Stockholm, Sweden

$T^{\mathrm{h}}$ he absolute configuration of $(-)$-norrangiformic acid, $1,(2 \mathrm{R}: 3 \mathrm{R})$-heptadecanetricarboxylic acid (2) has been determined by a stereospecific synthesis from 4 methyl -4- cyclohexen -(1R:2R) -dicarboxyl ic acid $(1)$. The antipode, $(+)$-norrangiformic acid, has been obtained by mild hydrolysis of naturally occurring $(+)$. rangiformic acid which is therefore methyl dihydrogen 1, (2S:3S)-heptadecanetricarboxylate (3). The position of the ester group is still uncertain.

It is interesting to note that rangiformic acid and the structurally related roccellic acid (4) have opposite configurations at posi-

* Part 26. Akermark, B. Arkiv Kemi 27 (1967) 10.

Acta Chem. Scand. 21 (1967) No. 2

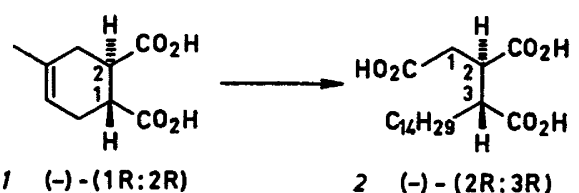

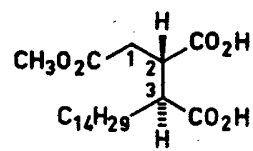

$3(+)-(25: 35)$

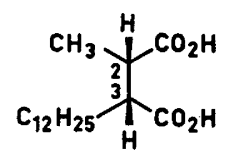

$4(t)-(2 S: 3 R)$ tion 3, which is presumably the position where oxaloacetate and the appropriate alkanoyl coenzyme $A$ are coupled during the biosynthesis of the compounds (3) and (4).

Experimental. (-)-4-Methyl-4-cyclohexene. $(1 R: 2 R)$-dicarboxylic acid (1) was obtained by repeated crystallizations from water of the brucine salt of trans-4-methyl-4-cyclohexene1,2-dicarboxylic acid (compare Ref. 1). On acidification of an aqueous solution of the salt, followed by extraction with ethyl acetate and evaporation of the solvent, a low yield of the acid (1) was obtained (5\%), partial melting at $139-140^{\circ}$, followed by recrystallisation and molting at $146-149^{\circ},[\alpha]_{\mathrm{D}}{ }^{25}-150 \pm 5^{\circ}$ (lit. ${ }^{1}$ m.p. $152-164^{\circ},[\alpha]_{D}^{25}+160 \pm 1^{\circ}$ for the enantiomer)

(-)-(3R:4R)-Dimethoxycarbonyl-6-oxoheptanoic acid. The dimethylester of (1) was prepared by methylation with diazomethane, $[\alpha]_{\mathrm{D}}{ }^{25}-150 \pm 5^{\circ}$ (neat), and then ozonised. The ozonides were decomposed with "activated zinc powder" 2 and the product recrystallised from light petroleum-ether $1: 1$ at $-20^{\circ}$ to give (-)-(3R:4R)-dimethoxycarbonyl-6-oxoheptanoic acid, m.p. $76-79^{\circ},[\alpha]_{\mathrm{D}^{25}}-70 \pm 5^{\circ}$ (c 0.97, chloroform). (Found: $C$ 50.6; H 6.2. Calc. for $\mathrm{C}_{11} \mathrm{H}_{18} \mathrm{O}_{7}$ : C 50.8; $\mathrm{H}$ 6.2).

(+)-2-Oxo-(4R:5R)-nonadecanedicarboxylic acid was prepared in a similar manner to the inactive compound ${ }^{2}$ by electrolytic coupling of (-)-3,4-dimethoxycarbonyl-6-oxoheptanoic acid and myristic acid, followed by hydrolysis. M.p. $119-123^{\circ},[\alpha]_{\mathrm{D}}{ }^{25}+52 \pm 5^{\circ}$ (c 1.0, ethanol). (Found: $\mathrm{C}$ 67.6; $\mathrm{H}$ 10.1. Calc. for $\mathrm{C}_{21} \mathrm{H}_{38} \mathrm{O}_{5}: \mathrm{C}$ 68.1; $\mathrm{H}$ 10.3).

(-)-1,(2R:3R)-Heptadecanetricarboxylic acid (2) was prepared by hypobromite oxidation of $(+)$-2-oxo-4,5-nonadecanedicarboxylic acid, ${ }^{2}$ followed by chromatography on ethanol washed silica (using light petroloum-ether as eluent) and recrystallisation from ethyl acetate. 